\title{
La noción de shareholder value y la teoría de los stakeholders: visión contemporánea del concepto de "interés social" desde una perspectiva de creación de valor ${ }^{*}$
}

The notion of "Shareholder value" and the theory of the "Stakeholder": Anglo-American vision of the "social interest" concept from a value creation perspective.

Recibido: 14 de junio de 2012 - Revisado: 09 de julio de 2012 - Aceptado: 24 de septiembre de 2012

Wilson Iván Morgestein Sánchez**

\section{Resumen}

Mediante el presente artículo se hace una exposición de lo que algunos califican como las aproximaciones modernas al concepto de "interés social": las teorías de la "shareholder value" y de los "stakeholders", las cuales son un aporte de la doctrina norteamericana al problema que plantea la gestión de la sociedad anónima de nuestro tiempo. Se presenta un estudio de sus antecedentes, concepción, evolución y relación con la sociedad anónima cotizada, para de esta forma determinar las consecuencias de aplicar la una o la otra en la administración de la gran sociedad de capitales.

Palabras clave

Interés social, shareholder value, stakeholders.

\begin{abstract}
By the present article, an exposition is made of what some label as the modern approaches to the concept of "social interest": The theories of the "shareholder value" and of the "stakeholders", which are a contribution of the American doctrine to the problem posed by the management of the corporations of our time. A study is offered here of their antecedents, conception, evolution and relation to the listed corporation to determine the consequences of applying one or another in the management of the great society of capitals.
\end{abstract}

\section{Key Words}

Social Interest, shareholder value, stakeholders.

\footnotetext{
Artículo de reflexión académica elaborado al interior del grupo de investigaciones en Derecho Privado San Alberto Magno, de la Facultad de Derecho de la Universidad Católica de Colombia.

** Abogado de la Universidad Santo Tomás de Bogotá. Especialista en Derecho Privado - Económico de la Universidad Nacional de Colombia. Magíster en Derecho Comercial de la Universidad Externado de Colombia. Profesor-Investigador de la Facultad de Derecho de la Universidad Católica de Colombia. Profesor de Derecho Comercial en las Facultades de Derecho de las Universidades Libre de Colombia y Antonio Nariño. Correo electrónico:

wimorgestein@ucatolica.edu.co ivanmorgestein@hotmail.com
} 


\section{Introducción}

Ya en varias oportunidades se ha puesto a consideración de la comunidad académica de nuestro país los trabajos de investigación en torno a las consideraciones del autor, el núcleo esencial, la piedra angular del moderno derecho de sociedades: el concepto de "interés social" (Morgestein, 2010, 2011). A través de estos escritos se presenta, a los distintos operadores jurídicos colombianos, lo que algún sector de la doctrina denomina "la aproximación tradicional" a esta noción (Sabogal Bernal, 2011), construida por las teorías contractualistas e institucionalistas del derecho de sociedades y la innegable conexión que presenta con diversas instituciones del derecho societario patrio.

Ahora bien, el concepto de "interés social", al ser una institución del derecho mercantil, tiene el deber de evolucionar al mismo paso que evolucionan las circunstancias que de orden filosófico, político, social, cultural y sobre todo económico rodean su interpretación y aplicación, y es así como en las últimas décadas se ha venido construyendo, por las doctrinas norteamericana y europea $^{1}$, lo que algunos llaman "la aproximación moderna" al concepto de "interés social" (Sabogal Bernal, 2011), a través de la formulación de las teorías de la shareholder value y de los stakeholders, las cuales son de aplicación preferente, casi que exclusiva, a la gran sociedad de capitales.

Al respecto Pablo Córdoba menciona que: "Dicho debate se ha presentado predominantemente respecto de la sociedad anónima abierta, en la que se presentan las características de una separación entre el control y la propiedad de la empresa, y de la negociación de sus títulos en el mercado público de valores, sin que por esta razón se pueda concluir que el tema no es predicable de las formas empresariales distintas a las sociedades anónimas que reúnen las anteriores características" (Córdoba Acosta, 2000 b. p. 157).

Los profesores Berle y Means fueron quizás los primeros en hacer un análisis científico sobre una circunstancia que ya se había adver- tido al interior de las sociedades de capitales en Estados Unidos y que ahora también se predica de todas aquellas sociedades que hacen parte de mercados públicos de valores muy desarrollados: la separación entre la titularidad del capital y la administración de las empresas ${ }^{2}$; la cual tiene como causa un hecho concreto: la notoria dispersión del capital social ${ }^{3}$.

Pues bien, es esa disyuntiva, es decir, la separación entre la titularidad de las acciones y la gestión de la actividad social, la que ha dado lugar a la construcción de las aludidas teorías de la shareholder value y de los stakeholders, las cuales, pretenden dilucidar el siguiente problema jurídico-económico: si los gestores de la sociedad anónima cotizada están administrando un capital que no les pertenece, en el ejercicio de sus funciones $i$ a favor de quién deben "crear valor": única y exclusivamente a favor de los accionistas (shareholders), o también deben "crear valor" en pro de los distintos grupos de interés (stakeholders) que se ven afectados por el desarrollo de la actividad empresarial? ${ }^{4}$

Pues bien, teniendo en cuenta que en torno al anterior problema científico giran las teorías de la shareholder value y de los stakeholders, la metodología jurídica de la que se va a hacer uso para el desarrollo del presente trabajo es de naturaleza esencialmente normativa, para lo cual se empleará un método básicamente cualitativo. Así, y en relación con las ya mencionadas teorías, se realizará un estudio de sus antecedentes, concepción, evolución y relación con la sociedad anónima abierta, para de esta forma determinar los postulados sobre los cuales descansan las mencionadas doctrinas.

\section{Discusión jurídica y resultados}

\section{Sociedad anónima: referencia histórica - noción - función económica y el problema de la "creación de valor".}

Diversas son las opiniones doctrinarias acerca del origen de la sociedad anónima en la 
época antigua; Brunetti afirma categóricamente que en el origen de la institución no hay relación alguna con la societas romana (Brunetti, 1960 en: Córdoba Acosta, 2000 p. 159); mientras que al decir de Córdoba Acosta: “... Observamos de todas maneras en la societas publicatorum el antecedente de cierta participación capitalista de algunos socios respecto de los cuales se atenúa el carácter personal de la sociedad y se predica una responsabilidad limitada, teniendo la vocación de que el inversionista no sea el directo administrador de los negocios o actividades de la sociedad". Por su parte, Ravassa encuentra un posible antecedente remoto de la sociedad anónima en las sociedades de acreedores del Estado constituidas en las asociaciones del Norte de Italia en la Baja Edad Media (Ravassa Moreno, 2006 p. 39) ${ }^{5}$.

Pero en lo que sí hay univocidad doctrinaria es en la afirmación de que fue a finales del siglo XVIII y principios del siglo XIX, que con ocasión de la revolución industrial y como consecuencia del auge de las grandes empresas -las cuales requerían magnas inversiones de capital-, los juristas de esa época, y frente a las necesidades de una naciente economía capitalista, sacaron nuevamente a la luz una especie societaria a la que ya le habían dado uso las monarquías absolutistas desde los inicios del siglo XVII en sus expediciones coloniales y la pusieron al servicio del capitalismo, para dar de esta forma nacimiento al capital con personalidad jurídica: la sociedad anónima (Ravassa Moreno, 2003 pp. 330-333 y Narváez García, 2008 p. 31). Sobre el tema de las compañías coloniales puede verse entre otros: Córdoba Acosta, 2000; Barrero Buitrago, 2001 y Peña Nossa, 2011 p. 143.

Pues bien, la sociedad anónima es el arquetipo de las sociedades mercantiles de capitales $^{6}$, y tal y como lo afirma el profesor Sául Sotomonte Sotomonte, (2005) "se ha convertido en la columna vertebral del desarrollo económico", resultando innegable la importancia que la institución tiene dentro del proceso productivo (p. 527); y ello es así por varias razones: (i) porque al lado del contrato se erige como la más eficiente herramienta que el derecho le ha aportado al sistema económico capitalista, (ii) porque constituye la especie societaria que mejor se adapta a las necesidades y a los intereses de la empresa de grandes dimensiones ${ }^{7}$, y (iii) por su capacidad para atraer grandes inversiones de capital (Córdoba Acosta, 2000 b. p. 159).

Ahora, se dijo desde la introducción del presente trabajo que en la sociedad anónima cotizada se presenta una disociación entre quienes la administran y entre quienes aportan los medios financieros a la misma, es decir los administradores o mánagers están gestionando los recursos de los inversionistas, circunstancia que presenta una serie de notas distintivas, dentro de las cuales, y siguiendo la autorizada opinión del profesor Pablo Andrés Córdoba, cabe destacar:

(i) Parece ser que esta separación entre la titularidad del capital y su administración se puede hallar en los orígenes mismos de la institución. En efecto, según Córdoba Acosta: "En la societas publicatorum recordemos como existía un administrador, manceps, y unos participantes capitalistas que corresponden, más o menos, a los modernos socios comanditarios en las compañías comanditarias".

(ii) La separación entre la propiedad y el control de la empresa es consecuencia de la necesidad de obtener recursos económicos adicionales a los que fueron aportados inicialmente por los accionistas que constituyeron la sociedad, y ello es posible movilizando y circulando grandes cantidades de capital a través de títulos (acciones) sin que sea menester acudir a engorrosos procedimientos que lo único que logran es obstaculizar la circulación de la riqueza (Berle, A. y Means, G., 1933 en: Córdoba Acosta, 2000 b. p. 164). 
(iii) El ejercicio de la actividad empresarial, a través de la gran sociedad de capitales, es desarrollado por personas idóneas (administradores o mánagers), quedando el accionista o inversionista relegado a integrar la asamblea gene$\mathrm{ral}^{8}$. Esto como consecuencia de dos factores esenciales; el primero: de la imperante necesidad, para las sociedades anónimas que negocian sus acciones en el mercado de valores, de lograr una mayor especialización del trabajo y de las funciones al interior de la institución, y la consecuente diferenciación entre labores técnicas y administrativas; y segundo: la existencia de una categoría de accionistas o inversores denominados especuladores o nómadas (Córdoba, 2000 b. p. 169) y que en palabras del maestro Ravassa (2006) “... su deseo no es convertirse en socio, sino invertir su capital o especular con él. Puede que unos días después vuelva a vender sus acciones por medio de la bolsa. Mientras tanto no ejerce sus derechos frente a la sociedad: no acude a votar a la asamblea, no reclama dividendos... (p. 160)"

El profesor Sotomonte (2005) apunta que:

(...) El hecho de que la sociedad anónima sea el centro de gravedad de la organización empresarial y que de ella dependa la obtención del hoy llamado nivel de vida sostenible hace que aún en las economías más desarrolladas el Estado se esté ocupando de la suerte de estas instituciones (p. 528)

Pues bien, esa preocupación de los distintos ordenamientos jurídicos por encontrar la forma más acertada de gobernar la sociedad anónima parte del reconocimiento de que en el desarrollo de la empresa societaria se pueden ver otros intereses distintos al interés particular de los accionistas; en efecto, en la moderna sociedad de capitales confluyen, al lado del interés de los inversionistas, el interés de directivos y trabajadores de la empresa y sus familias, consumidores y clientes de la misma, otras compañías del sector, asociaciones gremiales, el Estado, el mismo entorno y la comunidad en general, y a ello hay que agregarle que, como ya lo hemos dicho de manera insistente, la sociedad anónima cotizada es administrada por personas que no son las dueñas del capital social, entonces: ¿a favor de quién deben "crear valor" los administradores? ¿Deben hacerlo única y exclusivamente a favor de los inversores, o deben "crear valor" también a favor de los distintos grupos de interés que se ven afectados por el desarrollo de la empresa? Y si la respuesta fuera que deben "crear valor" a favor de los inversionistas, $¿$ a favor de qué tipo de inversionistas? ¿A favor de aquellos a los que solo les interesa el precio de sus acciones en el mercado bursátil (accionistas nómadas o especuladores), o también a favor de los inversores que además del valor patrimonial de sus acciones también están interesados en el gobierno de la persona jurídica $^{9}$ (accionistas institucionales)?

Pues bien, un aporte para encontrar una respuesta a los anteriores interrogantes lo hacen las teorías de la shareholder value y de los stakeholders, las cuales procedo a exponer a continuación.

\section{Teoría de la shareholder value}

La doctrina empresarial de la shareholder value $^{10}$ está dirigida hacia la creación y/o maximización de valor a favor del accionista, Luis Fernando Sabogal (2011) apunta que “... Se concibe el interés social ya no tanto bajo la idea de un beneficio económico encaminado a repartir las utilidades de los socios, sino a un interés que busca la maximización del valor actual de las acciones" (p. 5) y aunque comenzó a gestarse en los años ochenta, tuvo su auge, como forma de gobierno de las sociedades anónimas cotizadas, en la década de los noventa. Pero ahora, y como consecuencia de que los detractores de 
esta teoría encontraron en su aplicación una de las causas de una serie de crisis empresariales, la doctrina de la construcción de un mayor valor bursátil a favor del accionista ha perdido su predominancia como criterio orientador en la administración de la gran sociedad de capitales (Sánchez-Calero Guilarte, 2002 p. 28).

Resulta obvio que si se acoge esta teoría como brújula orientadora de la gestión de la sociedad anónima abierta, los administradores, en el ejercicio de sus funciones, deben privilegiar el interés de los inversores, el cual está dirigido a que los gestores de la compañía logren un aumento del valor de las acciones en el mercado bursátil, según Sánchez-Calero Guilarte (2002):

(...) Reclamar de los administradores la creación de valor implica exigirles que el valor de la acción expresado a través del mercado bursátil reproduzca fielmente el valor máximo que cabe atribuir al patrimonio de la sociedad. Esto pasa tanto por evitar inversiones poco rentables, como por obtener el máximo valor posible. La existencia de una discrepancia entre el valor de la empresa y el valor de la acción se convierte en motivo de censura hacia el administrador. El "diferencial de valor" es una invitación a la sustitución de los gestores ... (p. 33).

Sobre este particular, sostiene Numa Marín (2005):

(...) Visto así, el objetivo primordial de la junta directiva y del representante legal sería obtener la performance financiera de la sociedad... los accionistas esperan de los dirigentes una optimización en la gestión de las empresas, volumen de ventas, crecimiento en el mercado, aumento de precio de las acciones en bolsa (stock options) o plusvalía en la negociación de sus títulos y, al final de cuentas, aumento de dividendos o jugosas utilidades... Significa pues que los dirigentes están al servicio de los accionistas. Siempre deberán actuar en el interés de estos ya que son sus mandatarios -sus agentes, dicen los economistas-. En fin, algunos más radicales afirman que los accionistas son los propietarios de las empresas y los dirigentes son sus simples empleados..." (pp. 356-357).

Situación que, de conformidad con Sánchez-Calero Guilarte, se hace merecedora de varias observaciones: (i) el valor de las acciones en el mercado público de valores -bajo esta concepción de la shareholder value- deja de ser un mero reflejo de la situación económica de la compañía y pasa a convertirse en el mismo fin de la empresa, (ii) desde el punto de vista financiero es bien discutido el tema de la formación de los precios bursátiles, especialmente en el que tiene que ver con los métodos de valoración y los criterios de medición del valor que se dice creado, y (iii) la experiencia ha mostrado cómo una aparentemente correcta creación y/o maximización de valor para el accionista no siempre es legítima ni coincide con una adecuada gestión de la empresa. Sobre este último punto, Sánchez-Calero Guilarte pone como ejemplo, para el caso español, las sociedades cotizadas que prestan servicios públicos de suministros de energía, en donde los administradores tienen la obligación legal y reglamentaria de que la sociedad cuente siempre con los recursos adecuados para la correcta prestación del servicio.

Ahora, ¿cuáles son los efectos de una inadecuada creación y/o maximización de valor? Inicialmente, en las grandes sociedades cotizadas norteamericanas y europeas la consecuencia de una mala gestión de los intereses de sus accionistas -obviamente bajo el imperio de la teoría empresarial de la shareholder value - fue la de un cambio de control a través de la adquisición de las participaciones mayoritarias en el capital. 
Como quiera que, (...) Quienes consideran que el valor de las acciones es inferior al valor de la empresa, se verán tentados para adquirir su control y tratar de beneficiarse de una corrección de dicho diferencial..." (Sánchez-Calero Guilarte, 2002 p. 34). Por el contrario, “... Si la cotización refleja adecuadamente el valor de la empresa se diluirá el interés de los posibles adquirentes por llevar a cabo una adquisición del control y por provocar el consiguiente desplazamiento de los administradores (...) (p. 36).

Pero ahora, la tendencia es que los inversionistas institucionales: (i) separen de sus cargos a los administradores que no son capaces de crear y/o maximizar adecuadamente el "valor" para los inversores ${ }^{11}$, y (ii) denuncien a las sociedades en las que se observe un desajuste entre el valor que cabe atribuirle a la empresa y la evolución de la acción en bolsa (SánchezCalero Guilarte et al. 2006, p. 37).

Para finalizar este acápite, se retoma lo expuesto por el profesor español Sánchez-Calero Guilarte, quien pone de presente como sí la teoría de la shareholder value lo que trata es de que los administradores de las grandes sociedades de capitales favorezcan los intereses de sus inversionistas, pues lo más lógico sería que se estimule a los gestores para que creen y/o maximicen el "valor" de los inversores, y a este respecto han sido tan variadas como controvertidas las soluciones que se han propuesto. Se ha dicho que con el fin de atraer a los administradores hacia los intereses de los accionistas resultaría conveniente que se les otorgara a los gestores una participación en el capital social, o que su remuneración dependiera de la rentabilidad de la acción en el mercado de valores, pero la experiencia ha demostrado: (i) lo difícil que es que converjan plenamente los intereses de administradores y accionistas, (ii) que el riesgo vinculado a la tenencia de acciones de la propia sociedad no puede ser el mismo para el inversor que para el gestor, como quiera que el primero puede disminuir ese riesgo diversificando sus inversiones de capital, mientras que el administrador es más vulnerable al curso negativo de la acción (Rappaport, 1998, citado por Juan Sánchez-Calero Guilarte. 2002 p. 36) y (iii) el pretendido afán de hacer converger los intereses de accionistas y administradores puede llevar a un inmoral enriquecimiento de estos últimos. (Sánchez-Calero Guilarte, 2002 pp. 35-36).

\section{Teoría de los stakeholders ${ }^{12}$}

El auge mundial de la Responsabilidad Social de la Empresa es la génesis de la teoría de los stakeholder ${ }^{13}$-como criterio de gestión de la sociedad anónima abierta-, y la misma pregona la defensa de los diversos grupos de interés que se ven afectados por el desarrollo de la actividad económica, intentando dejar por el piso la tesis de que los administradores, en el ejercicio de sus funciones, deben "crear valor" única y exclusivamente a favor de los inversores ${ }^{14}$.

El solo postulado sobre el cual descansa esta doctrina es revolucionario, y por lo mismo no ha escapado a múltiples y agudas críticas, dentro de las cuales se puede: (i) determinar qué es lo más conveniente para la comunidad no es cosa que les corresponda a los que administran las sociedades mercantiles, sino a los titulares de los poderes públicos del Estado, (ii) el tema de la Responsabilidad Social Empresarial puede ser utilizado por administradores negligentes para excusar una deficiente gestión de la empresa, (iii) el afán por atender una diversidad de intereses puede llevar a un debilitamiento de la compañía y a una pérdida de su competitividad en el mercado y (iv) la experiencia ha demostrado que ese criterio "social" de gestión ha concluido en reestructuraciones traumáticas o absorciones de la empresa por terceros (Sánchez-Calero Guilarte, 2002, p. 37).

Ahora, los defensores de la teoría de los stakeholders han contestado a las críticas formuladas en contra de esa doctrina empresarial, 
entre otros, con los siguientes argumentos: (i) el problema de la Responsabilidad Social de la Empresa no es de la órbita exclusiva del derecho de sociedades, sino que, por el contrario, en muchas legislaciones el asunto tiene un origen en la Ley Fundamental de cada país ${ }^{15}$ y (ii) si se propaga la idea de que solo los accionistas son quienes van a recibir los beneficios que se reporten en el desarrollo de la actividad empresarial, sin participar a nadie de los mismos, poco a poco la comunidad va a terminar rechazando a los inversionistas, sumiendo a la sociedad comercial en un profundo caos. (Yepes, y otros, 2007, p. 126).

\section{Hacia una visión actual de la shareholder value}

En este punto de la exposición se quiere destacar una de las tantas y tan valiosas reflexiones del profesor español Juan Sánchez-Calero Guilarte (2002) en la cual advierte que al adoptar una noción del concepto de "interés social" no necesariamente se tienen que excluir unos intereses a favor de otros, sino de lo que se trata es de establecer una jerarquía de intereses, para que al tutelar directamente algunos de ellos, los otros, aunque de manera indirecta, también se vean favorecidos, y tal y como lo pone de presente el mencionado tratadista, la doctrina de la shareholder value "... entiende, precisamente, que la primaria protección de los accionistas comportará otros beneficios para las demás partes involucradas en la empresa (p. 32) ${ }^{" 16}$.

La que se denominaría una visión actual de la shareholder value intenta "...demostrar que la creación de valor para el accionista tiene efectos positivos para los demás titulares de intereses vinculados con la actividad empresarial...", (Sánchez-Calero Guilarte, 2006, p. 37). y también " $(. .$.$) considerar que la aplicación$ de esa doctrina de la maximización del valor de la empresa no supone desconocer la defensa de otros intereses igualmente afectados por la marcha de la sociedad: la satisfacción de aquel criterio benéfico para los accionistas ha de im- plicar la coincidente atención hacia los demás intereses de otros grupos de sujetos igualmente vinculados con la marcha de la sociedad". (Sánchez-Calero Guilarte, 2006, p. 63)

Esta visión de la shareholder value no es nueva, desde hace ya varios años un sector de los partidarios de esta doctrina empresarial ha admitido que la defensa primaria de los intereses de los accionistas no tiene necesariamente que llevar al desconocimiento de los beneficios de los otros grupos de intereses que se ven afectados por el desarrollo de la actividad económica, y así se ha entendido que al proteger a los inversores se puede también "crear valor" para los demás stakeholders.

Esta concepción de la shareholder value tampoco ha sido ajena a las críticas, y siguiendo la exposición de Luis Fernando Sabogal, (2011, p. 8) estas han sido básicamente dos: i) la presencia en todo el mundo de grandes crisis empresariales, que se dice han estado favorecidas o suscitadas, entre otras circunstancias, por los gobiernos societarios inspirados en esta doctrina, y ii) la inusitada fuerza que en los últimos años ha adquirido el movimiento de la Responsabilidad Social Empresarial y su corolario: el Buen Gobierno Corporativo.

Pero lo cierto es que las anteriores críticas son válidas frente a un modelo "tradicional" de la shareholder value, porque la que yo denomino visión "actual" de esta teoría propugna por que los administradores de las grandes sociedades de capitales, en el desarrollo de las tareas que les son propias, al lado de los intereses de los accionistas, consideren también los intereses de otros grupos de personas, para de esta forma "crear un valor integral para la empresa". (Sabogal, 2011, p. 8)

En trabajos anteriores, en los cuales se ha abordado el concepto de "interés social" desde una perspectiva "tradicional", he defendido la teoría neocontractualista del derecho de sociedades básicamente con el argumento de que 
el neocontractualismo del derecho societario constituye una simbiosis entre los principios del contractualismo y los postulados del institucionalismo, recogiendo de esta manera las experiencias tanto positivas como negativas de las escuelas contractualistas e institucionalistas, e intentando armonizarlas con las actuales realidades no solo jurídicas, sino también filosóficas, políticas, culturales y, sobre todo, económicas de las naciones.

En esta oportunidad la posición que se representa es la de apoyo a los defensores de la teoría de la shareholder value; pero a aquellos que consideran que se deben tener en cuenta las vicisitudes que una interpretación a ultranza de la misma ocasionó en épocas anteriores, a los que son conscientes de que los postulados sobre los cuales se construyó la misma se deben armonizar con las normas de rango constitucional de cada Estado, a quienes no desechan con argumentos falsos los aportes que la teoría de los stakeholders puede hacer para la administración de las sociedades mercantiles de capitales, y a los que abogan porque en la aplicación de la shareholder value se tengan en cuenta las demandas que el mundo entero le hace a la empresa contemporánea.

\section{Conclusiones}

Fue a finales del siglo XVIII y principios del siglo XIX, que con ocasión de la revolución industrial y como consecuencia del auge de las grandes empresas -las cuales requerían grandes inversiones de capital-, los juristas de esa épo$\mathrm{ca}, \mathrm{y}$ frente a las necesidades de una naciente economía capitalista, sacaron nuevamente a la luz una especie societaria a la que ya le habían dado uso las monarquías absolutistas desde los inicios del siglo XVII en sus expediciones coloniales y la pusieron al servicio del capitalismo, para dar de esta forma nacimiento al capital con personalidad jurídica: la sociedad anónima.

En la sociedad anónima cotizada se presenta una disociación entre quienes la adminis- tran y entre quienes aportan los medios financieros a la misma.

La separación entre la propiedad y el control de la empresa es consecuencia de la necesidad de obtener recursos económicos adicionales a los que fueron aportados inicialmente por los accionistas que constituyeron la sociedad.

Si se acoge la teoría de la shareholder value como brújula orientadora de la gestión de la sociedad anónima abierta, los administradores, en el ejercicio de sus funciones, deben privilegiar el interés de los inversores, el cual está dirigido a que los gestores de la compañía logren un aumento del valor de las acciones en el mercado bursátil.

La teoría de los stakeholders pregona la defensa de los diversos grupos de interés que se ven afectados por el desarrollo de la actividad económica, intentando dejar por el piso la tesis de que los administradores, en el ejercicio de sus funciones, deben "crear valor" única y exclusivamente a favor de los inversores.

Una visión "actual" de la teoría de la shareholder value admite que la defensa primaria de los intereses de los accionistas no tiene necesariamente que llevar al desconocimiento de los beneficios de los otros grupos de intereses que se ven afectados por el desarrollo de la actividad económica, y así se ha entendido que al proteger a los inversores se puede también "crear valor" para los demás stakeholders.

\section{Notas}

${ }^{1}$ En razón a que, como se explicará a lo largo de este trabajo, el origen del debate se localiza en países con un mercado bursátil verdaderamente grande. Cabe destacar: (i) la sección 172 de la Companies Act 2006 del Reino Unido, y a cuyo tenor: "Duty to promote the success of the company. (1) A director of a company must act in the way he considers, in good faith, would be most likely to promote the suc- 
cess of the company for the benefit of its members as a whole, and in doing so have regard (amongst other matters) to - (a) the likely consequences of any decision in the long term, (b) the interests of the company's employees, (c) the need to foster the company's business relationships with suppliers, customers and others, (d) the impact of the company's operations on the community and the environment, (e) the desirability of the company maintaining a reputation for high standards of business conduct, and (f) the need to act fairly as between members of the company. (2) where or to the extent that the purposes of the company consist of or include purposes other than the benefit of its members, subsection (1) has effect as if the reference to promoting the success of the company for the benefit of its members were to achieving those purposes. (3)The duty imposed by this section has effect subject to any enactment or rule of law requiring directors, in certain circumstances, to consider or act in the interests of creditors of the company", y (ii) el artículo 64 del Código das Sociedades Comerciais de Portugal: "(Dever de diligência). Os gerentes, administradores ou directores de uma sociedade devem actuar com a diligência de um gestor criterioso e ordenado, no interesse da sociedade, tendo em conta os interesses dos sócios e dos trabalhadores".

${ }^{2}$ Cfr. (Reyes Villamizar, 2006 p. 3). Sobre este particular, afirma el profesor Córdoba Acosta: "Es verdad, hoy la gran empresa o sociedad de capitales es manejada por individuos que nada tienen que ver con la propiedad de las acciones en las que se divide el capital de las empresas; es decir, estas pueden ser consideradas como centros en los cuales unos sujetos, conocidos como managers, manejan la riqueza de otras personas, denominadas inversionistas". (Córdoba Acosta, 2000 p. 39).

${ }^{3}$ El profesor Guillermo Cabanellas de las Cuevas, en el prefacio a la obra del profesor Francisco Reyes Villamizar. Derecho societario... cit., p. 16, apunta: “... Mientras que en el derecho estadounidense el problema central es evitar que los administradores usen y abusen del control efectivo que ejercen sobre las sociedades abiertas frente a la dispersión del capital accionario, en América Latina el problema central es el de los abusos de los socios mayoritarios y la correlativa impotencia de los minoritarios, y ello así pues aún en las sociedades abiertas casi siempre es posible identificar en los países latinoamericanos un individuo o un conjunto pequeño y cohesionado de individuos que tienen suficientes acciones como para gozar el control efectivo de la sociedad". Por su parte, sostiene Córdoba Acosta: “... No se puede olvidar que la estructura empresarial de cada país es fundamental para determinar la perspectiva del debate, pues es normal que este se presente casi exclusivamente respecto de las sociedades con títulos inscritos en las bolsas de valores en sistemas como el estadounidense y el inglés, cambiando obviamente la orientación en el caso colombiano, en el cual existe un incipiente mercado bursátil incapaz de irrigar recursos suficientes a las empresas". (Córdoba Acosta, 2000b p. 157).

4 "La sociedad anónima se presenta entonces como un campo de batalla y un juego de poderes: poderes jurídicos y poderes económicos, poderes de dirigentes y poderes de accionistas, poderes de mayoritarios y poderes de minoritarios, poderes de decisión y poderes de control, poderes del órgano de decisión y poderes del juez, hoy superintendencia...". (Numa Marín, 2005 pp. 351-352). "El debate sobre cuál es el propósito de la sociedad encontró un impulso singular con respecto a las sociedades cotizadas en la doctrina estadounidense. El punto de partida fue la publicación en 1932 de la conocida y repetidamente citada obra de Berle, A. A. / Means, G. C., The Modern Corporation and Private Property, a la que siguió un intenso debate entre el primero de los autores y Merrick. Berle defendía que todas las actuaciones del equipo gestor debían estar orientadas al beneficio de los accionistas, mientras que Merrick defendía una visión de la sociedad mercantil como una institución económica que junto a una función de obtención de beneficios debía atender a su finalidad social". (Fernández Torres, I.; Fuente Naharro, M. y Sánchez-Calero Guilarte, J., 2006, p. 14 ) 
5 “... El tránsito de los banqueros a los bancos se produce a través de las asociaciones de acreedores del Estado. Los príncipes de las ciudades del norte de Italia eran muy aficionados a la guerra. Pero como la guerra cuesta mucho dinero y los impuestos no bastaban para cubrir los gastos, se hacía necesario recurrir a empréstitos públicos, suscritos por los banqueros y los poderosos. La garantía de devolución era el dinero que se pensaba recoger con los impuestos de años sucesivos. En otras palabras, estos banqueros y demás prestamistas lo que hacían era adelantar dinero "a cuenta". Para asegurarse la devolución de lo prestado, exigieron de los príncipes una delegación de prerrogativas públicas consistente en poder cobrar ellos mismos los impuestos. Con este objeto constituyeron sociedades, aportando cada socio el monto de su acreencia con el Estado y respondiendo frente a terceros hasta el importe de dicho monto únicamente. Como además las partes de interés (la palabra 'acción' solo aparece en 1606) eran libremente transmisibles, se considera que es posible encontrar aquí el antecedente remoto de la sociedad anónima".

6 “... Es decir aquellas en las que la calidad de socio deviene fungible, motivo por el cual la persona del contratante no es lo importante, sino que la prevalencia la tiene el capital".

7 “... Como fueron y son la necesidad de recursos, la eliminación o atenuación del riesgo -responsabilidad en derecho- y la fácil circulación de la riqueza... La carencia de recursos se solucionó concibiendo a este tipo societario como un gran fondo de inversión. La atenuación del riesgo se logró estableciendo la no responsabilidad de los accionistas por el pasivo social y la fácil circulación de la riqueza se obtuvo representando el capital social en títulos llamados acciones, dotando a estas últimas de los mecanismos de circulación de los títulos valores" (Sotomonte Sotomonte, 2005).

8 “... En realidad la asamblea general de accionistas tendrá la oportunidad de examinar la labor de los expertos solamente en contadas ocasiones, aprobando su gestión o reprobándola, lo que es poco probable, sin contar con toda la información necesaria, prácticamente a ciegas" (Córdoba Acosta. 2000, p. 163). “... La asamblea de accionistas no es el órgano más adecuado para lograr un control efectivo de la gestión, a lo que se suma la dispersión del accionariado que produce un órgano meramente deliberativo cuya reunión es difícil y costosa" (Córdoba Acosta. 2000, p. 168).

${ }^{9}$ Para entender lo difuso que puede resultar el concepto de valor, se recomienda la lectura de la obra del maestro Gerardo José Ravassa Moreno (2006, p. 106 y ss).

${ }^{10}$ En este punto de la exposición se hacen dos precisiones: (i) Sin lugar a dudas, y tal como se ha venido advirtiendo, la teoría de la shareholder value encuentra sus antecedentes en las doctrinas contractualistas del derecho de sociedades, y (ii) Los aportes a la construcción de esta teoría provienen básicamente de las ciencias económicas y financieras, siendo mínima la contribución del derecho, la cual básicamente ha estado centrada en torno al tema del gobierno corporativo, partiendo del concepto de "interés social". (Paz-ares, 2004, 15, citado por Juan Sánchez-Calero Guilarte. (2002, p.29) Rodríguez Artigas y otros, coords, 2002).

11 “... En el caso de las grandes sociedades resulta obvio que el principal objetivo de los inversores es la búsqueda de una mayor rentabilidad de sus acciones en el mercado de valores, y, por tanto, los administradores estarán indiscutiblemente orientados, e incluso presionados, a alcanzar ese objetivo so pena de no obtener los anhelados bonos (como forma de retribución) o ser retirados del cargo...". (Fernando Sabogal, 2011 p. 7). En cambio, “... Aquellos administradores que hayan acreditado una capacidad para favorecer a los accionistas a través de la creación de valor serán invitados a desarrollar una misión similar en otras sociedades" (Sánchez-Calero Guilarte, 2002, p. 37). 
${ }^{12} \mathrm{Al}$ decir de Luis Fernando Sabogal Bernal (2011): “... En esta misma línea de las corrientes institucionalistas, actualmente existe una doctrina con un amplio reconocimiento internacional comparado, que recoge y actualiza esta idea pluralista del interés social con el nombre de teoría del stakeholder value..." (p. 9).

13 “... El concepto de stakeholders se consolidó cuando se empezó a apreciar la inseparabilidad de las partes que conforman la comunidad y que integran el circuito corporativo; surgió, además, de la necesidad de tomar en cuenta todas las consecuencias de las acciones y decisiones de la empresa sobre la sociedad como un todo, tanto en sus aspectos internos como externos...". ( Peña Collazos, W.; Sánchez Maldonado, L. F. y Yepes, G. 2007. Responsabilidad social empresarial. Fundamentos y aplicación en las organizaciones de hoy, p. 124. Bogotá: Universidad Externado de Colombia).

${ }^{14}$ Sobre este particular, dice la profesora Amparo Jiménez (2008): “... Este modelo -el de los stakeholders- parte del principio de que la empresa no solamente se debe a sus accionistas, sino a todas las partes afectadas por sus decisiones, o a las partes que la pueden afectar en el pasado, presente o futuro...". Jiménez, A. (octubre de 2008). 'Hacia una práctica gerencial responsable: conceptos, prácticas y perspectivas actuales', en Revista de Derecho Privado, 40, p. 7. Bogotá: Universidad de los Andes. Recuperado de http://derechoprivado.uniandes.edu. co/index.php?numero=40\&tipos=Ensayos. Por su parte, afirma la profesora Elsa González: “... Esta teoría permite pensar un nuevo paradigma empresarial, donde existe una comprensión de la empresa plural. Por tanto, la empresa no es cosa de uno (accionista o propietario), ni exclusivamente de dos (propietarios y trabajadores), sino que la empresa debe ser entendida desde la pluralidad de 'agentes' -los que afectan- que intervienen en ella y, por tanto, la hacen posible, así como desde todos aquellos 'pacientes' -los que son afectados- por la organización empresarial...". (González Esteban, E. 'La teoría de los stakeholders: un puente para el desarrollo prácti- co de la ética empresarial y de la responsabilidad social corporativa', p. 208, en Veritas, II(17).

15 Para el caso colombiano, el artículo 333 de la Constitución Nacional dispone: “... La empresa, como base del desarrollo, tiene una función social que implica obligaciones...". Por su parte, el artículo 58 superior establece: "La propiedad es una función social que implica obligaciones...".

${ }^{16}$ En otro escrito de su coautoría, el mismo Sánchez-Calero plantea: “... Es compatible la vigencia del interés social, con prácticas o estrategias de RSE que parten de la consideración directa de intereses extraños a aquel interés social... El problema de la compatibilidad es, por tanto, un falso dilema. Por supuesto la rentabilidad y la RSE van unidas con frecuencia, pues la una lleva a la otra y viceversa..." (Sánchez-Calero Guilarte; Fernández Torres.; Fuente Naharro, 2006, p. 16-17).

\section{Referencias}

Barrero Buitrago, A. (2011). Manual para el establecimiento de sociedades, 5. ${ }^{\text {a }}$ edición. Bogotá: Librería Ediciones del Profesional.

Córdoba Acosta, P. A. (2000a). 'El gobierno de la empresa y el derecho', en Revista de Derecho Privado, 5. Bogotá: Universidad Externado de Colombia.

Córdoba Acosta, P. A. (2000b). 'La autonomía privada, el gobierno societario y el derecho de sociedades', en Revista de Derecho Privado, 6. Bogotá: Universidad Externado de Colombia.

Fernández Torres, I.; Fuente Naharro, M. y Sánchez-Calero Guilarte, J. (2006). La primacía de los accionistas y la RSE: ¿una compatibilidad posible? La responsabilidad social corporativa y sus actores. Mitos y desafios de la responsabilidad social corporativa. Universidad Complutense de Madrid. 
González Esteban, E. 'La teoría de los stakeholders: un puente para el desarrollo práctico de la ética empresarial y de la responsabilidad social corporativa', en Veritas, II(17).

Jiménez, A. (2008, octubre) 'Hacia una práctica gerencial responsable: conceptos, prácticas y perspectivas actuales', en Revista de Derecho Privado, 40. Bogotá: Universidad de los Andes. Recuperado de http:// derechoprivado.uniandes.edu.co/index. php?numero $=40 \&$ tipos $=$ Ensayos

Morgestein Sánchez, W. I. (2010, diciembre). 'La SAS en el derecho societario colombiano: de un institucionalismo de forma hacia un nuevo contractualismo', en Via inveniendi et iudicandi, 10. ${ }^{\text {a }}$ edición. Bogotá: Universidad Santo Tomás. Recuperado de http:// viei.usta.edu.co/index.php?option $=$ com content\&view $=$ article \&id $=101$ :la-sasen-el-derecho-societario-colombianode-un-institucionalismo-de-forma-hacia-un-nuevo-contract\&catid=37:reflexiones-academicas $\&$ Itemid $=57$

Morgestein Sánchez, W. I. (2011, junio-diciembre). 'El concepto de interés social y su impacto en el derecho de sociedades colombiano', en Revista e-mercatoria, 10(2). Bogotá: Universidad Externado de Colombia. Recuperado de http://www.emercatoria.edu.co/ PAGINAS/VOLUMEN10/02.html\#a123

Narvaéz García, J. I. (2008). Teoría general de las

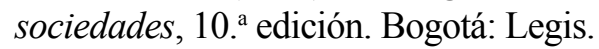

Numa Marín, M. M. (2005). 'Interés común de los asociados, interés de la sociedad e interés de la empresa. Reflexiones en torno a la toma de decisiones en las sociedades anónimas', en La empresa en el siglo XXI. Bogotá: Universidad Externado de Colombia.

Peña Nossa, L. (2011). De las sociedades comerciales, 6. ${ }^{a}$ edición. Bogotá: Universidad Santo Tomás-Temis.
Ravassa Moreno, G. J. (2003). Derecho comercial. Bienes mercantiles, Tomo I, $1 .^{\text {a }}$ edición, reimpresión. Bogotá: Universidad Santo Tomás-Gustavo Ibáñez.

Ravassa Moreno, G. J. (2006). Títulos valores. Nacionales e internacionales. Bogotá: Doctrina y Ley.

Reyes Villamizar, F. (2006). Derecho societario en Estados Unidos. Introducción comparada, 3. ${ }^{a}$ edición. Bogotá: Legis.

Sabogal Bernal, L. F. (2011, enero-junio). 'El interés social: apuntes teóricos en el marco socio-económico del derecho de empresa', en Revista e-mercatoria, 10(1). Bogotá: Universidad Externado de Colombia.

Sánchez-Calero Guilarte, J. (2002). 'Creación de valor, interés social y responsabilidad social corporativa', en Derecho de sociedades anónimas cotizadas, T. II, Rodríguez Artigas y otros (coords.), Cizur Menor, Madrid.

Sánchez-Calero Guilarte, J., Fuente Naharro, M. y Fernández Torres, I. (2006). 'La primacía de los accionistas y la RSE: ¿una compatibilidad posible?', en $L a$ responsabilidad social corporativa y sus actores. Mitos y desafios de la responsabilidad social corporativa. Universidad Complutense de Madrid.

Sotomonte Sotomonte, S. (2005). 'El fortalecimiento de la sociedad anónima por vía jurisprudencia', en La empresa en el siglo $X X I$. Bogotá: Universidad Externado de Colombia.

Yepes, G., Peña Collazos, W., y Sánchez Maldonado, L. F. (2007). Responsabilidad social empresarial. Fundamentos y aplicación en las organizaciones de hoy. Bogotá: Universidad Externado de Colombia. 